\section{Highly cis-selective synthesis of iodo-aziridines using diiodomethyllithium and in situ generated $N$-Boc-imines $\dagger$}

\author{
James A. Bull,* Tom Boultwood and Thomas A. Taylor \\ Received 27th September 2012, Accepted 2nd November 2012 \\ DOI: $10.1039 / \mathrm{c} 2 \mathrm{cc} 37029 \mathrm{~h}$

\begin{abstract}
The first preparation of iodoaziridines is described. The addition of diiodomethyllithium to $\mathrm{N}$-Boc-imines affords these novel aziridines in high yields. The reaction proceeds in one-pot via a highly diastereoselective cyclisation of an amino gem-diiodide intermediate.
\end{abstract}

Aziridines continue to provide both structural fascination, ${ }^{1}$ and important synthetic intermediates for wide ranging applications in chemical synthesis. ${ }^{2}$ Consequently, diverse synthetic methods for their preparation have been disclosed. ${ }^{3}$ In recent years the functionalisation of intact aziridine rings has become important, allowing access to a variety of aziridine derivatives from single precursors. In particular, anionic functionalisation of aziridines, ${ }^{4}$ in the absence of a stabilising group, has been mediated either by functional group exchange, ${ }^{5}$ or by direct deprotonation at the most acidic site. ${ }^{6}$ Recently, Vedejs and co-workers reported the palladium catalysed cross coupling of aziridine metal species, formed by $\mathrm{Bu}_{3} \mathrm{Sn}-\mathrm{Li}$ exchange, with aryl halides. ${ }^{7}$ We envisaged that more efficient routes to suitably functionalised aziridines, that would enable regiocontrolled and diverse derivatisation of the intact ring, could find numerous applications in synthesis.

$C$-Heteroatom substituted aziridines can dramatically influence the reactivity and stability of the 3-membered ring. ${ }^{8}$ Chloro-aziridines, in particular dichloroaziridines, often formed by the reaction of dichlorocarbenes and imines, ${ }^{9,10}$ are widely used in the preparation of $\mathrm{N}$-containing heterocycles. ${ }^{8}$ Bromoaziridines are more difficult to access, and have been reported on only a few occasions. Ziegler first formed bromoaziridines by a Barton decarboxylation-bromination from aziridine carboxylates, affording a mixture of cis/trans-isomers. ${ }^{11}$ These were used as radical precursors in the synthesis of mitomycin-like antitumour agents. ${ }^{12}$ Yudin has reported bromoaziridines through an $N$-transfer approach, generating a nitrene under oxidative conditions, ${ }^{13}$ as has Huang using $\mathrm{TsNBr}_{2}{ }^{14}$ Additionally, Oshima reported the intermediacy of bromoaziridines in the preparation of silyl aziridines, proposing an in situ elimination

Department of Chemistry, Imperial College London, South Kensington, London SW7 2AZ, UK. E-mail: j.bull@imperial.ac.uk; Tel: + $44(0) 2075945811$

$\dagger$ Electronic supplementary information (ESI) available: Experimental and characterization data and NMR spectra $\left({ }^{1} \mathrm{H}\right.$ and $\left.{ }^{13} \mathrm{C}\right)$ for all novel compounds. See DOI: $10.1039 / \mathrm{c} 2 \mathrm{cc} 37029 \mathrm{~h}$

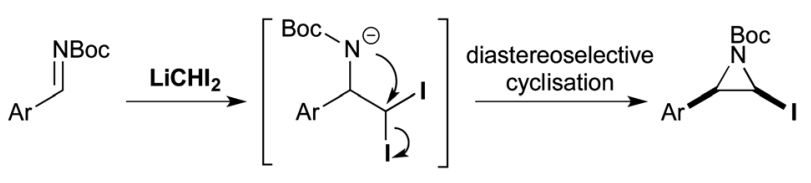

Scheme 1 Proposed route to iodoaziridines.

of bromide. ${ }^{15}$ Mono- and di-fluoroaziridines have also been recently reported. ${ }^{16}$

Iodoaziridines, on the other hand, are unknown in the literature to date. We chose to explore the possibility of forming iodoaziridines, as a potential reactive substrate for cross coupling, which should also provide precursors for anionic or radical functionalisation. Here we report the preparation of this new functional group, in high yields and excellent cisstereoselectivity in one step from simple $N$-Boc-imine-sulfinic acid adducts.

We proposed an addition-cyclisation protocol to access iodoaziridines from imines using diiodomethyllithium, analogous to the aza-Darzens reaction (Scheme 1). ${ }^{17,18}$ Recently Charette and Bull utilised diiodomethane anions at $-78^{\circ} \mathrm{C}$ to prepare alkyl diiodides by alkylation, ${ }^{19}$ and to form styryl halides by alkylation/ elimination, ${ }^{20}$ but diiodomethyllithium remains an underutilised reagent. ${ }^{21}$ Importantly, whereas in the aza-Darzens reaction itself the diastereochemistry of the aziridine product is determined in the initial addition, here, due to the symmetrical nature of the diiodomethyllithium nucleophile the cyclisation step would be diastereodetermining.

The stability of potential iodoaziridines was naturally a significant concern, due to potential loss of iodide amongst other potential decomposition routes. We elected to examine $N$-Boc imines to provide an electron-withdrawing group on $N$ as well as offering potential for further functionalisation or ring opening.

Initial investigations concentrated on the addition of diiodomethyllithium to phenyl $\mathrm{N}$-Boc imine to afford the aminodiiodide. Diiodomethyllithium was preformed by deprotonation of $\mathrm{CH}_{2} \mathrm{I}_{2}$ with LiHMDS at $-78{ }^{\circ} \mathrm{C}$ prior to addition of the imine. ${ }^{22}$ Both the imine and imine- $\mathrm{HO}_{2} \mathrm{STol}$ adduct $1 \mathrm{a}$ were examined, with the latter preferred for practical simplicity, generating the imine in situ by deprotonation with excess base. $^{23,24}$ Careful optimisation of the reaction conditions was undertaken, including the equivalents of base and $\mathrm{CH}_{2} \mathrm{I}_{2}$, the use of Lewis basic additives, as well as concentration and the solvent ratio (a mixture of THF and ether was essential). ${ }^{19 a}$ The optimal 


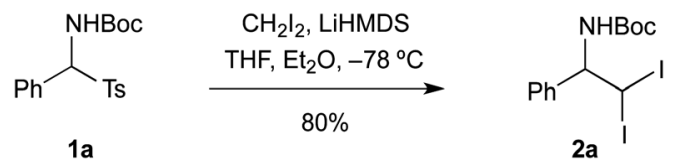

Scheme 2 Formation of amino-diiodide 2a.

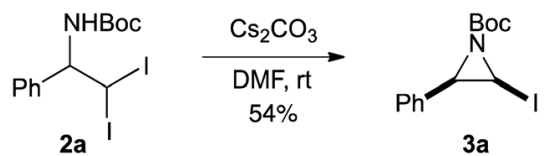

Scheme 3 Cyclisation to iodoaziridine 3a promoted by $\mathrm{Cs}_{2} \mathrm{CO}_{3}$.

conditions (3.0 equiv. $\mathrm{CH}_{2} \mathrm{I}_{2}, 2.6$ equiv. LiHMDS, THF/Et ${ }_{2} \mathrm{O}$, $-78{ }^{\circ} \mathrm{C}$ ) provided amino-diiodide $2 \mathrm{a}$ in $80 \%$ yield (Scheme 2 ).

We next assessed the conversion of diiodide $\mathbf{2} \mathbf{a}$ to aziridine 3a using a variety of bases and Lewis acids to promote the cyclisation. Under these conditions, multiple pathways could be conceived: the desired cyclisation may occur to form either syn or anti-aziridines, cyclisation to the oxazoline, or alternatively elimination to the vinyl iodide. Pleasingly, the use of $\mathrm{Cs}_{2} \mathrm{CO}_{3}$ in DMF produced an effective cyclisation, providing iodoaziridine 3a (54\% yield, Scheme 3$){ }^{25}$ Remarkably, aziridine 3a was stable to isolation and could be purified on silica gel without decomposition. ${ }^{26}$ Furthermore, exclusive formation of the cis-aziridine was observed indicating a highly stereoselective cyclisation step was occurring.

Having proved iodoaziridine 3a was indeed a viable structure, the possibility of a one-pot synthesis was investigated. Cyclisation could be promoted by subsequent warming of the reaction mixture, after the initial addition of $\mathrm{LiCHI}_{2}$ was complete, under otherwise similar reaction conditions. Subtle control of the reaction temperature profile proved to be critical.

The addition of $\mathrm{LiCHI}_{2}$ to the generated imine occurred very rapidly at $-78{ }^{\circ} \mathrm{C},{ }^{27,28}$ but the intermediate was stable at this temperature (Table 1, Entry 1). Warming to rt by removing the flask from the dry ice bath led to inseparable mixtures of iodoaziridine 3a with the elimination product 4a. Cyclisation was observed to occur only slowly at $-20{ }^{\circ} \mathrm{C}$, with diiodide $\mathbf{2 a}$ the major product after $60 \mathrm{~min}$. At $0{ }^{\circ} \mathrm{C}$ the diiodide reacted completely to afford a $3: 1$ mixture of iodoaziridine $\mathbf{3 a}$ and the elimination product iodide $\mathbf{4 a}$, and rapid warming to $\mathrm{rt}$ in a water bath gave an improved ratio (entries 2-4). Ultimately the

Table 1 Selected optimisation: one-pot preparation of iodoaziridines ${ }^{a}$

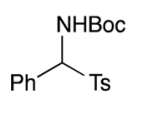

$1 a$
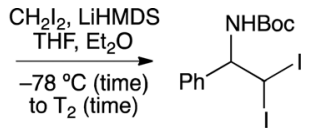

2a
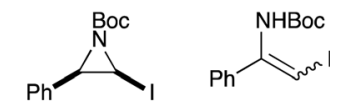

$4 a$

\begin{tabular}{ccccc}
\hline Entry & $\begin{array}{c}\text { Time at } \\
-78{ }^{\circ} \mathrm{C}^{b}(\min )\end{array}$ & $\mathrm{T}_{2}\left({ }^{\circ} \mathrm{C}\right)$ & $\begin{array}{c}\text { Time } \\
\text { at } \mathrm{T}_{2}(\mathrm{~min})\end{array}$ & $\begin{array}{c}\text { Product ratio } \\
\mathbf{2 a}: \mathbf{3} \mathbf{a}: \mathbf{4 a}\end{array}$ \\
\hline 1 & 60 & $-{ }^{c}$ & - & $\mathbf{2 a}$ only $^{d}$ \\
2 & 30 & -20 & 60 & $6: 2: 1$ \\
3 & 30 & 0 & 90 & $-: 3: 1$ \\
4 & 20 & $\mathrm{rt}$ & 90 & $-: 10: 1$ \\
5 & 10 & 30 & 10 & $\mathbf{3 a}$ only
\end{tabular}

${ }^{a}$ Imine- $\mathrm{HO}_{2} \mathrm{STol}$ adduct 1 (0.3 mmol), $\mathrm{CH}_{2} \mathrm{I}_{2}$, (3 equiv.), LiHMDS (2.6 equiv.), $\mathrm{THF} / \mathrm{Et}_{2} \mathrm{O}(3: 1),-78{ }^{\circ} \mathrm{C}$ to $30{ }^{\circ} \mathrm{C}$. ${ }^{b}$ Time following addition of 1a. ${ }^{c}$ Reaction quenched at $-78{ }^{\circ}$ C. ${ }^{d}$ As Scheme 2; yield $80 \%$. $^{e} 83 \%$ yield.
Table 2 Scope of one-pot synthesis of iodoaziridines ${ }^{a}$
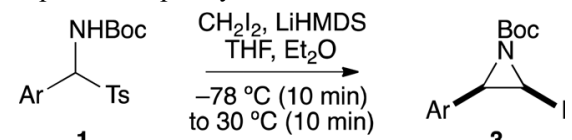

\begin{tabular}{ccccc}
\hline Entry & Ar & Yield $(\%)$ & d.r. & \\
\hline 1 & $\mathrm{Ph}$ & 83 & $>95: 5$ & $\mathbf{3 a}$ \\
2 & & $88^{c}$ & $>95: 5$ & \\
3 & 4-Tolyl & 96 & $>95: 5$ & $\mathbf{3 b}$ \\
$4^{d}$ & 2-Tolyl & 89 & $90: 10(>95: 5)$ & $\mathbf{3 c}$ \\
5 & 2-Napthyl & 92 & $>95: 5$ & $\mathbf{3 d}$ \\
6 & 4- $t$ BuPh & 67 & $>95: 5$ & $\mathbf{3 e}$ \\
7 & 4-ClPh & 51 & $>95: 5$ & $\mathbf{3 f}$ \\
$8^{d}$ & 2-ClPh & 52 & $>95: 5$ & $\mathbf{3 g}$ \\
9 & 4-BrPh & 42 & $>95: 5$ & $\mathbf{3 h}$ \\
10 & 4-FPh & 76 & $>95: 5$ & $\mathbf{3 i}$ \\
$11^{f}$ & 3-OMePh & 77 & $>95: 5$ & $\mathbf{3 j}$ \\
12 & 4-CF 3 Ph & 13 & & $\mathbf{3 k}$ \\
13 & 3-Pyridyl & 49 & & $\mathbf{3 l}$
\end{tabular}

${ }^{a}$ Imine- $\mathrm{HO}_{2} \mathrm{STol}$ adduct 1 ( $\left.0.6 \mathrm{mmol}\right), \mathrm{CH}_{2} \mathrm{I}_{2}$, (3 equiv.), LiHMDS (2.6 equiv.), $\mathrm{THF} / \mathrm{Et}_{2} \mathrm{O}(3: 1),-78{ }^{\circ} \mathrm{C}$ to $30{ }^{\circ} \mathrm{C} .{ }^{b}$ d.r. of crude mixture by ${ }^{1} \mathrm{H}$ NMR. Where $>95: 5$ is stated, the minor diastereoisomer could not be observed by ${ }^{1} \mathrm{H}$ NMR. $d . r$. of purified compound indicated in parentheses where relevant. ${ }^{c}$ Reaction performed on a 3 mmol scale. ${ }^{d}$ Warmed to $30{ }^{\circ} \mathrm{C}$ for $30 \mathrm{~min}$ as required to induce cyclisation. ${ }^{e}$ Also contained diiodide $\mathbf{2} \mathbf{g}$ in crude mixture, which was isolated in $5 \%$ yield. ${ }^{f}$ Purified on neutral alumina due to decomposition on silica gel.

rate of warming was shown to be crucial in avoiding elimination. Therefore the cyclisation was performed in a water bath at $30{ }^{\circ} \mathrm{C}$, to ensure rapid and reproducible warming. This completely prevented the elimination pathway and iodoaziridine 3a could be isolated cleanly in excellent yield (Table 1, entry 5, Table 2 entry 1). ${ }^{29}$ Performing the reaction on a $3 \mathrm{mmol}$ scale afforded similarly excellent yield and selectivity (Table 2, Entry 2).

Variation of the aromatic group of the imine with alkyl and napthyl substituents gave the corresponding iodoaziridines in high yields, and exclusively as the cis-isomers (Table 2, entries 3-6). The ortho-tolyl substrate displayed more reluctance to cyclise, requiring a longer time at the elevated temperature $(30 \mathrm{~min})$ to achieve complete cyclisation from the amino-diiodide (entry 4), presumably due to unfavourable steric interactions.

Next halogenated aromatics were examined, which were well tolerated by the reaction conditions (entries 7-10). With orthochlorophenyl (Entry 8) cyclisation was more significantly slowed presumably due to coordination of the lone pairs on the orthosubstituent with the lithium cation in the intermediate. Notably in this example the trans-iodoaziridine was observed. ${ }^{30}$ All other examples were isolated in $>95: 5$ cis-selectivity by ${ }^{1} \mathrm{H}$ NMR.

The 3-methoxyphenyl bearing imine was also tolerant of the reaction conditions but required the short reaction times to prevent decomposition (Entry 11). As electron rich $N$-Boc aziridines are prone to $S_{N} 1$-type opening, purification required chromatography on neutral alumina to prevent decomposition. Electron poor aryl-imines were successful (entries 12-13) but with lower yields due to increased amounts of elimination and other side product formation. Alkyl imines were generally not successful, for example with cyclohexyl imine-adduct (1m), only the corresponding diiodide (2m) was isolated in $29 \%$ yield. The use of $\mathrm{CH}_{2} \mathrm{Br}_{2}$ in the place of $\mathrm{CH}_{2} \mathrm{I}_{2}$ under otherwise identical 


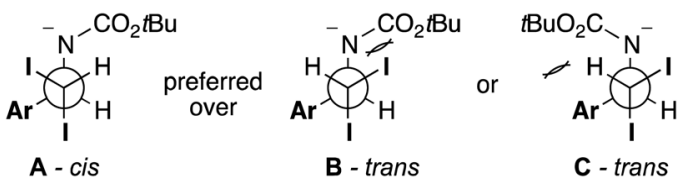

Scheme 4 Orientation for cyclisation; A preferred (Ar and I cis).

conditions with 1a led to the formation of the corresponding bromoaziridine (5) with exclusive cis-stereochemistry in an unoptimised yield of $30 \%$.

Our proposal for the cis-selectivity in forming the iodoaziridines is based on steric factors (Scheme 4). ${ }^{31}$ The aryl and Boc groups are likely to adopt an anti-orientation preferentially, providing two conformations (A and B) with $\mathrm{N}$ and $\mathrm{I}$ in an anti-periplanar arrangement appropriate for cyclisation. We propose that an unfavourable interaction between the nondisplaced iodide with the Boc group is dominant in the cyclisation transition state where the $N$-atom becomes $\mathrm{sp}^{3}$ hybridised. Hence the non-displaced iodine prefers to adopt a position away from the bulk of the Boc group and so gauche to the $\mathrm{Ph}$ group, resulting in the cis-aziridine configuration.

In summary, we report the first examples of iodoaziridines. The use of diiodomethyllithium with careful temperature control allows either the isolation of the amino-diiodide or complete cyclisation to the iodoaziridine with very high cis-selectivity, and both with excellent yields. We are currently developing methods for the functionalisation of iodoaziridines to various aziridine derivatives, which will be reported in due course.

For financial support we gratefully acknowledge the EPSRC (Career Acceleration Fellowship to JAB), the Ramsay Memorial Trust (Research Fellowship 2009-2011 to JAB), The Royal Society for a research grant, the Nuffield foundation and Pfizer for UG bursaries (TT, TB), and Imperial College London. Thank you to Prof Alan Armstrong for generous support and advice.

\section{Notes and references}

1 (a) Aziridines and Epoxides in Organic Synthesis, ed. A. K. Yudin, Wiley-VCH, Weinheim, 2006; (b) J. B. Sweeney, Chem. Soc. Rev., 2002, 31, 247; (c) A. Padwa and S. S. Murphree, Arkivoc, 2006, iii, 6 .

2 (a) G. Cardillo, L. Gentilucci and A. Tolomelli, Aldrichimica Acta, 2003, 36, 39; (b) I. C. Stewart, C. C. Lee, R. G. Bergman and F. D. Toste, J. Am. Chem. Soc., 2005, 127, 17616; (c) P. Lu, Tetrahedron, 2010, 66, 2549.

3 For recent reviews see: (a) H. Pellissier, Tetrahedron, 2010, 66, 1509; (b) J. Sweeney, Eur. J. Org. Chem., 2009, 4911; (c) Y. Zhang, Z. Lu and W. Wulff, Synlett, 2009, 2715; (d) I. D. G. Watson, L. Yu and A. K. Yudin, Acc. Chem. Res., 2006, 39, 194.

4 (a) S. Florio and R. Luisi, Chem. Rev., 2010, 110, 5128; (b) T. Satoh, Chem. Rev., 1996, 96, 3303; (c) S. Florio, Synthesis, 2012, 44, 2872.

5 (a) E. Vedejs and W. O. Moss, J. Am. Chem. Soc., 1993, 115, 1607; (b) E. Vedejs and J. Little, J. Am. Chem. Soc., 2002, 124, 748; (c) T. Satoh, T. Sato, T. Oohara and K. Yamakawa, J. Org. Chem., 1989, 54, 3973; (d) T. Satoh, M. Ozawa, K. Takano, T. Chyouma and A. Okawa, Tetrahedron, 2000, 56, 4415; (e) T. Satoh, R. Matsue, T. Fujii and S. Morikawa, Tetrahedron, 2001, 57, 3891; (f) S. D. Wiedner and E. Vedejs, Org. Lett., 2010, 12, 4030.

6 (a) P. Beak, S. Wu, E. K. Yum and Y. M. Jun, J. Org. Chem., 1994, 59, 276; (b) D. M. Hodgson, P. G. Humphreys and J. G. Ward, Org. Lett., 2005, 7, 1153; (c) D. M. Hodgson, B. Stefane, T. J. Miles and J. Witherington, J. Org. Chem., 2006, 71, 8510; (d) D. M. Hodgson, P. G. Humphreys and S. P. Hughes, Pure Appl. Chem., 2007, 79, 269; (e) D. M. Hodgson, P. G. Humphreys, S. M. Miles, C. A. J. Brierley and J. G. Ward, J. Org. Chem., 2007, 72, 10009; $(f)$ D. M. Hodgson, P. G. Humphreys, Z. Xu and J. G. Ward, Angew. Chem., Int. Ed., 2007, 46, 2245; (g) F. Affortunato, S. Florio, R. Luisi and B. Musio, J. Org. Chem., 2008, 73, 9214; (h) B. Musio, G. J. Clarkson, M. Shipman, S. Florio and R. Luisi, Org. Lett., 2009, 11, 325; (i) F. Schmidt, F. Keller, E. Vedrenne and V. K. Aggarwal, Angew. Chem., Int. Ed., 2009, 48, 1149; (j) J. Huang, S. P. Moore, P. O'Brien, A. C. Whitwood and J. Gilday, Org. Biomol. Chem., 2009, 7, 335. 7 J. M. Nelson and E. Vedejs, Org. Lett., 2010, 12, 5085.

8 G. S. Singh, M. D'hooghe and N. De Kimpe, Chem. Rev., 2007, 107, 2080

9 (a) A. G. Cook and E. K. Fields, J. Org. Chem., 1962, 27, 3686; (b) J. A. Deyrup and R. B. Greenwald, J. Am. Chem. Soc., 1965, 87, 4538; (c) M. Mihara, Y. Ishino, S. Minakata and M. Komatsu, J. Org. Chem., 2005, 70, 5320.

10 H. Yamanaka, J. Kikui, K. Teramura and T. Ando, J. Org. Chem., 1976, 41, 3794.

11 F. E. Ziegler and M. Belema, J. Org. Chem., 1994, 59, 7962.

12 (a) F. E. Ziegler and M. Belema, J. Org. Chem., 1997, 62, 1083; (b) F. E. Ziegler and M. Y. Berlin, Tetrahedron Lett., 1998, 39, 2455 .

13 L. B. Krasnova and A. K. Yudin, Org. Lett., 2006, 8, 2011.

14 R. Shen and X. Huang, Org. Lett., 2009, 11, 5698.

15 K. Yagi, H. Shinokubo and K. Oshima, Org. Lett., 2004, 6, 4339.

16 E. Van Hende, G. Verniest, R. Surmont and N. De Kimpe, Org. Lett., 2007, 9, 2935.

17 For the formation of terminal aziridines using iodomethyllithium see: (a) J. M. Concellón, H. Rodríguez-Solla, P. L. Bernad and C. Simal, J. Org. Chem., 2009, 74, 2452; (b) J. M. Concellón, H. Rodríguez-Solla and C. Simal, Org. Lett., 2008, 10, 4457.

18 For a related reaction using $\mathrm{LiCHCl}_{2}$ see: (a) J. A. Deyrup and R. B. Greenwald, Tetrahedron Lett., 1965, 321; (b) Also see ref. 15.

19 (a) J. A. Bull and A. B. Charette, J. Org. Chem., 2008, 73, 8097; (b) J. A. Bull and A. B. Charette, J. Am. Chem. Soc., 2010, 132, 1895.

20 J. A. Bull, J. J. Mousseau and A. B. Charette, Org. Lett., 2008, 10, 5485

21 (a) M. B. Boxer and H. Yamamoto, Org. Lett., 2008, 10, 453; (b) D. S. W. Lim and E. A. Anderson, Org. Lett., 2011, 13, 4806.

22 The use of NaHMDS to form $\mathrm{NaCHI}_{2}$ resulted in decomposition.

23 M. Petrini, Chem. Rev., 2005, 105, 3949.

24 For the preparation of imine sulfinic acids: A. G. Wenzel and E. N. Jacobsen, J. Am. Chem. Soc., 2002, 124, 12964.

25 Compound 3a was assigned as the cis-aziridine on the basis of IR stretch $\left(\mathrm{C}=\mathrm{O} ; 1724 \mathrm{~cm}^{-1}\right)$ and characteristic ${ }^{1} \mathrm{H}$ NMR coupling constants $(J=5.4$ for aziridine $\mathrm{CH})$.

26 Iodoaziridine 3a was stable to silica gel and in solution. On concentration the neat compound showed significant sensitivity to light leading to decomposition. Iodoaziridines were stored as stock solutions in dichloromethane at $-20{ }^{\circ} \mathrm{C}$. Under these conditions 3a was stable for $>4$ weeks.

27 Low temperature is required for the initial addition to ensure the stability of $\mathrm{LiCHI}_{2}$.

$28 \mathrm{See} \mathrm{ESI} \dagger$ for further details on ${ }^{1} \mathrm{H}$ NMR sampling studies into the rate of addition and cyclisation. This supports our mechanistic hypothesis of addition followed by cyclisation at elevated temperatures, rather than an alternative mechanism via diiodocarbene. Quenching the reaction at $-78{ }^{\circ} \mathrm{C}$ with $\mathrm{D}_{2} \mathrm{O}$ (forming 2a) did not lead to any incorporation of deuterium in place of the $\mathrm{CHI}_{2}$ proton, but partial incorporation at $\mathrm{NH}$. This suggests that the intermediate diiodide is not deprotonated to the carbenoid under the reaction conditions.

29 A possible explanation for effect of rate of warming on product distribution is that elimination is caused by excess $\mathrm{LiCHI}_{2}$ which decomposes rapidly on warming to non-basic species, preventing the undesired elimination reaction.

30 For $o$-substituted aryl imines influencing $d . r$. in aziridine formation, see: A. B. McLaren and J. B. Sweeney, Org. Lett., 1999, 1, 1339.

31 Alternative explanations involving electronic factors may be possible. See $\mathrm{ESI} \dagger$ for further discussion. 